International Journal of Social Sciences and Humanities
Available online at http://sciencescholar.us/journal/index.php/ijssh
Vol. 2 No. 3, December 2018, pages: 117 123
e-ISSN: 2550-7001, p-ISSN: 2550-701X
https://doi.org/10.29332/ijssh.v2n3.217

\title{
Communication Strategy for English Guides: Tourism Area in Lombok Island
}

\author{
Dende Maya Umrah a, Mahyuni ${ }^{\mathrm{b}}$, Syahdan c,
}

Article history: Received 10 May 2018, Accepted: 31 August 2018, Published: 8 November 2018

\section{Correspondence Author ${ }^{a}$}

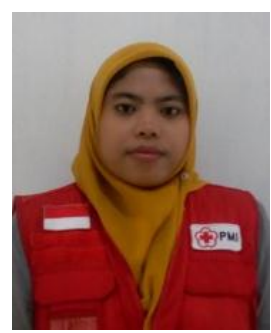

Keywords

Communication

strategies;

English speaking tourists;

Lombok tour guide;

Performance;

Skills;

\section{Abstract}

The popularity of Lombok in the tourism sector has been experienced by many foreign tourists. According to The West Nusa Tenggara Bureau of Statistic 2017, there are 1.404 .328 people who have come to Lombok as foreign tourists, $10,3 \%$ of them used the Lombok Guide to arrange their trip. Based on the data, this research will discuss how communication strategies between Lombok tourist guides and English speaking tourists will be conducted. This research will focus on the common communication strategies that are being used by the guides. The source of this research will be the guides who work regularly at one of the travel agencies in Mataram city. The data will be collected from the recording of Lombok Guides and the English speaking tourists' conversations. This research reveals nine types of communication strategies such as message abandonment, topic avoidance, circumlocution, approximation, use all-purpose words, prefabricated, non-linguistic, stalling/time gaining, and overelaboration. Finally, of the 63 total acts, the most common communication strategies or the dominant ones are message abandonment with a total of 15 acts about $23,8 \%$, less dominant is an approximation with a total of 5 acts about $7,9 \%$ and the least dominant are over-elaboration with a total of 2 acts about $3,2 \%$. In summary, the guides need to improve their skills and performance to tackle the problems that are present in the research.

e-ISSN: 2550-7001, p-ISSN: 2550-701X ๑ Copyright 2018. The Author. SS Journals Published by Universidad Técnica de Manabí. This is an open-access article under the CC BY-SA 4.0 license (https://creativecommons.org/licenses/by-sa/4.0/) All rights reserved.

a Mataram University, Indonesia

b Mataram University, Indonesia

c Mataram University, Indonesia 


\section{Contents}

Abstract

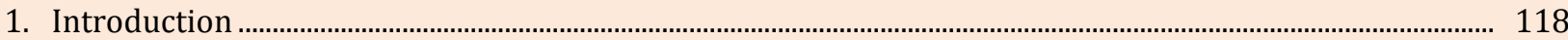

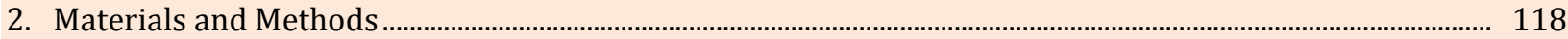

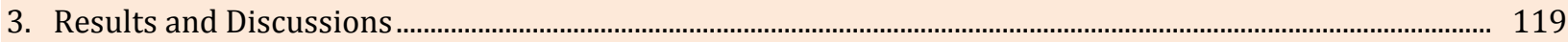

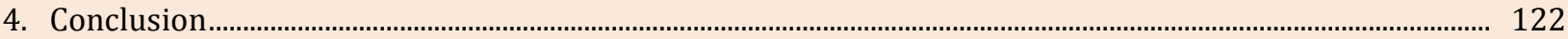

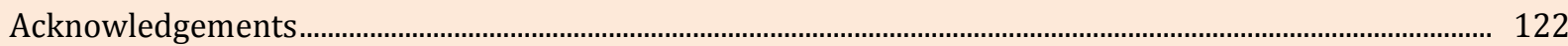

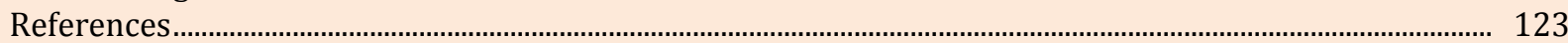

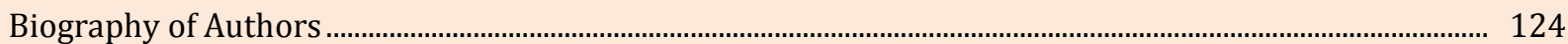

\section{Introduction}

Nowadays, tourism is one of the interesting fields in Lombok. Many people whose love traveling have interested to visit Lombok Island, there is an international and national tour. In the tourism term, international tourist called overseas tourist meanwhile national tourist called a domestic tourist. According to West Nusa Tenggara Bureau of Statistic 2017 of Tourism, there are 10,03\% of tourists use a travel agency to help them find a suitable destination place during their stay in Lombok. There are around 1.404 .328 people who are coming to Lombok as overseas tourists. They come to Lombok for many purposes, such as traveling, honeymoon, study-tour, even business meetings. Therefore, Lombok guides are needed to support the overseas tourists who come to Lombok. In this case, the English speaking tourist guide will be more useful. Based on that phenomenon, the study of communication strategies will be conducted. The data will be collected at several tourist destinations in Lombok Island (Bialystok, 1983).

Furthermore, there are several aspects which related to communication strategies. For an instance, nonlinguistic aspect related to all of the non-verbal action which used to assist the speaker during the interaction in order to convey the message clearly. The last reason, this study will increase the reader's knowledge and will assist the Lombok tour guides to improve their ability to be more professional.

\section{Materials and Methods}

This study typically observes the Lombok Tour Guide's strategies in communicating with English speaking tourists. The purpose of this research is to prove the common strategies are used, the pattern and the factors that affect the patterns of communication strategies which used during the live-interaction between Lombok Tour Guide and English speaking tourists (Astawa et al., 2017). The sample of this study is the guide who works regularly at ones of travel agencies in Mataram. Collecting the data is an important part of this study, there are several techniques such as observation, recording, note taking and interview. It is also applied to the data analysis process. There are several techniques will be used to analyze the data, such as identification, classification, description, and explanation.

\section{Theory}

Studies about the difficulties and strategies of communicating are common issues in teaching English as a Foreign Language. Meanwhile, the studies about communication strategies in non-school-based activities are rare. Due to this matter, the researcher tried to improve and apply several theories to complete this study. Several studies have been done in regard to such a topic. According to Tarone (1983:62) shows there are five points of communication strategies such as "avoidance, paraphrase, conscious transfer, appeal for assistance, and mime". Avoidance is divided into "topic avoidance" and "message abandonment". In this case, topic avoidance is related to avoid the concept which is the item or the structure is not recognized by the speaker, while message abandonment related to not be able to finish the message of communication. A paraphrase is divided into "approximation"," word coinage", and "circumlocution". Meanwhile, Dőrnyei (1995:58) divides communication strategy into two main strategies, "avoidance" and "compensatory strategies". There are 
fourteen communication strategies which classified by Dőrnyei such as message abandonment, topic avoidance, circumlocution, approximation, prefabricated, word coinage, use the all-purpose word, nonlinguistics signal, literal translation, foreignizing, appeal for help, and stalling/ time gaining. And according, Cohen et al., (1983:6) discusses some communication strategies such as "transfer from the native language, overgeneralization, prefabricated pattern, over-elaboration, epenthesis, and avoidance".

In this study, the researcher will use an ethnographic research as the research design. Ethnographies are based on first-hand observations of behavior in a group of people in their natural setting. Investigators report on what they see and hear as they observe what is going on around them. Duranti (1997:85), states that "ethnography is the written description of the social organization, social activities, symbolic and material resources, and interpretive practices characteristic of a particular group of people". It is related to people's daily interaction, the way they communicate with each other.

\section{Results and Discussions}

After conducting the research, the researcher found the use of common communication strategies based on data collected. This chapter also presents the type of communication strategies (CS) which existed in the conversation between Lombok guide and English speaking tourists. Based on the data collected, one action also possible to have two or more communication strategies in it.

The following is the information about communication strategies which has been analyzed on data collected. There are fourteen types of communication strategies, but only nine are being used by the participants.

Table 1

Common Communication Strategies

\begin{tabular}{lcccc}
\hline \multicolumn{1}{c}{ CS } & CS Amount & Total CS Action & $100 \%$ & Percentage \\
\hline Message Avoidance & 16 & 87 & 100 & 18.4 \\
Topic Avoidance & 7 & 87 & 100 & 8.0 \\
Circumlocution & 2 & 87 & 100 & 2.3 \\
Approximation & 8 & 87 & 100 & 9.2 \\
Use All Purpose Word & 3 & 87 & 100 & 3.4 \\
Word Coinage & 0 & 87 & 100 & 0.0 \\
Prefabricated & 12 & 87 & 100 & 13.8 \\
Non-Linguistics signal & 17 & 87 & 100 & 19.5 \\
Literal Translation & 0 & 87 & 100 & 0.0 \\
Foreignizing & 0 & 87 & 100 & 0.0 \\
Code-Switching & 0 & 87 & 100 & 0.0 \\
Appeal for Help & 0 & 87 & 100 & 0.0 \\
Stalling or Time Gaining & 18 & 87 & 100 & 20.7 \\
Over-elaboration & 4 & 87 & 100 & 4.6 \\
\hline
\end{tabular}

The most common communication strategies or the dominant ones are stalling/time gaining with a total of 18 acts about $20,7 \%$, less dominant are over-elaboration with a total of 4 acts about $74,6 \%$ and the least dominant are circumlocution with a total of 2 acts about 2,3\%.

This chapter will discuss the result of the discussion from this study. There are nine communication strategies which find in this study. According to Tarone (1983), there are avoidance and paraphrase strategies. Meanwhile, Dőrnyei (1995) elaborate it into avoidance and compensatory strategies.

Here the result of an analysis of this study. The conversation between the guide (G) and tourist (T). On the actions (17) G: yeaa iss aa Gili Meno also nice. In this action, there two types of communication strategies such as message abandonment and stalling/time gaining. Actually, the guide wants to explain more about Gili Meno, but he chooses not to do that since they are in Sendang Gile. It means, he intentionally made an unfinished statement. He also uses hesitation device, for example; aa..iss aa. Meanwhile, in (32) T: yea... its

Umrah, D. M., Mahyuni, -, \& Syahdan, -. (2018). Communication strategy for English guides: tourism area in Lombok island. International Journal of Social Sciences and Humanities, 2(3), 117-124. https://doi.org/10.29332/ijssh.v2n3.217 
very quiet, it's in the middle...; 39) G: interesting name, make people would like to.. ; (60) T: I know because I don't want to busy, we always stay in Bali but another part of Indonesia; (188) T: ehmm, kind of...; (192) T: yea travel writer; (103) G: today there is no rain I forget to bring you the raincoat(laughing); (327) T: aa Monday afternoon Tuesday Thursday Wednesday we go to the airport; and (428)G: yea.llike 3 days rain, one day, for now, is dry,,... These actions only have one CS called message abandonment, since the tourists did not finish the message clearly.

This action, (41) G: yeaa just enjoy....; has two types of CS such as message abandonment and non-linguistic signal. Here the message is to enjoy the sunbathing, but instead if saying enjoy the sunbathing the guide used gesture by pointing to the sun and make gesture such a people laid down in the seaside, he also intended to show the picture people who enjoy the sunbathing.

In this action, (43) G: we pass, there are three CS such as topic avoidance, message abandonment, and nonlinguistics signal. Here the guide tried to avoid the topic about seaside and sunbathing, by pointing the path to enter the Senaru waterfall. So, he changed the topic to waterfall, but the problem is he only said "we pass", it means the message not finish yet. He could say "we pass the path to Senaru, we should go back first". Meanwhile, (77) G: and in West Lombok 35, and about $50 \%$ of people live there... aaa and 3 in here; (255) G: they will cook there is rest...aa of rice they will be dried it's not,,, aaa so something...aa here just dried it; and (257) G: and then after that when they collecting...aa by sun heat and then they would like to fry,,,aa the rice they make .. with that,; these actions used three of CS such as stalling/time gaining, message abandonment, and non-linguistics signal. The guide intended unfinished his message, also using hesitation device, and support by the hand gesture. In (77) he should say 35 gili, and in (255) ...there is rest (the guide mention about rest area or lodging the rice field), instead of saying lodging he points directly to the lodging around the rice field in Senaru village.

In another hand, (372) G: the mountain..... here is,,, aa,, the foot; and (374) G: here the Rinjani......Both of the actions used two type of CS such as message abandonment and non-linguistics signal. Here the message is unfinished, he pointing the soil to make the tourist understand his explanation. Instead of saying slope he said foot, he also used hesitation device.

In the actions, (47) G: but you would stop here to take a picture?; (139) G: in Taiwan you have many rice field there?; (207) G: also the address...... you happy?; (267) G: yea... higher now... we feel cooler .. the mountain; (298) G: well; (300) G: ok, then....; and (306) G: how many days you stay here in Lombok? These actions only used one type of CS called topic avoidance, the guide try to avoid and change the topic.

Different with actions (67) G: cheaper and they prefer to come to Lombok in a big group and they relief for individual because it's cheaper; and (205) G: more appetizer than information. Both of that action only used one type of CS called circumlocution. The guide intended to say something using more word that into direct meaning. Meanwhile, in actions (11) G: oww Gili air.. yeah yeah its more a..aa..aa \{confused to description not crowded, more like silent\}; (23) G: gili trawangan is the...... \{wondering the right words\}biggest one, is the.... many tourists like over there.... \{use hand gesture, dance like in the pub\} our party. Both of the actions used three types of CS such as approximation, non-linguistic signal, and stalling/time gaining]. In (11) he used hesitation device to pause the action, he wants to say silent but cannot find the word. And for (23) he said biggest instead of crowded and using hand gesture like dancing in the pub.

In this action (83) G: it's the last month there is only smoke.... Is only ashes,,, amount of smoke, earthquake; only used two of CS such as prefabricated and approximation. He said the amount of smoke instead of a lot of smoke, and also he wants to say there are a lot of ashes, smoke.

In this action, (85)G: but the smoke too, but it was making...also.... not good for the normal flight... the ashes disturb the pilot, and the flight is canceled. He used two of CS such as approximation and overelaboration. He said not good instead of bad; and for (135) G: yeah geopark the place people can do research for the volcano for the flora and fauna, like botanical. This action used two types of CS such as approximation and prefabricated. Here, the guide tried hard to retrieve the suitable word, finally, he used botanical instead of the natural environment.

Meanwhile, in (201) G: it's also for free in every hotel..big hotel..they just got the money from the appetizer, he only used two types of CS such as non-linguistics signal and approximation. He used hand gesture to make sure it is big, but instead of the famous hotel, he said big hotel. And for (241) G: we have electrical here but the people...aa far away..really quite here.... Aa.. very far away from the busy one...He used two types of CS such as stalling/time gaining and non-linguistics signal. He used hesitation device and also hand gesture to explain far 
away. In action, (261) G: there is also with nasi where.. aa after cooking the people still rest in that place \{pointing the lodging in the rice field\} and they will dry it... yes. He used three types of CS such as stalling/time gaining, prefabricated, and approximation. He tried to retrieve the word, but he used nasi instead of rice.

In another hand, in (101) G: because wet because of its rain season; (137) G: yea, because of a lot of kind of flora.... Botanical; (174) T: big company asus; and (13) G: yea quite, tranquility. These actions used two types of CS such as prefabricated and use the all-purpose word. The guide tried to retrieve the suitable word, and in the end, he used the word which has more than one meaning. Meanwhile, in (61) G: there a lot of tourist.. maybe like you see in gili right?; and (145) G: yeah just like us.. the tropical fruits...

Both of these actions used one type of CS called prefabricated. The guide tried to remember suitable words. Different with, (159) G: because there is also just like in the... aaaa.....badminton.....tournament; and (171) G: Acer...acer...and what is also? (try to remember the other product) Acer and then.. Both of these actions used two types of CS such as prefabricated and stalling/time gaining. The guide tried to remember the suitable words, and gain the time by using hesitation device and eye contact. So that, the tourist can accept his message.

In actions, (235) G: yeah.. because at the night we don't have any....(thinking);

(253) G: at our home usually our mother when the rice....the cooking; and (356) G: yea... [laughing] for Saturday and Sunday there..aa also local [he means local tourists], but yea much foreigners. These actions used two types of CS such as a prefabricated and non-linguistic signal. The guide tried to remember the suitable words, but in the end, he used gesture to relay the message. In (235) he cannot find a suitable word, then he used driver gesture to explain not many people drove in the night at North Lombok. And for (253) He used gesture done to explain when the rice cooked. And for, (261) G: there is also with nasi where.. aa after cooking the people still rest in that place \{pointing the lodging in the rice field\} and they will dry it... yes. Here, the guide used three types of CS such as stalling/time gaining, prefabricated, and approximation to make the message clearly conveyed.

In the actions, (33)G: ow in the middle of the island?; and (87) G: it's the last year I mean in the last month of the year I mean November it was the worst for the Rinjani eruption because it making close for 1 week for the airport like in Bali...also here... because of the wind.... to the west, so Bali about 1 week close. Meanwhile, in (319) T: ok, can i??; (366) G: this way up... aaa very aaa; and (398) G: we need to go.... to up there.

Those actions are used one type of CS called non-linguistics signal, he used gesture to convey the message. In (33) he used a hand gesture to make clear meaning. Different with (87) he used a hand gesture to imitate the wind to explain about the wind-blown direction. As (319) The tourist use a hand gesture to imitate how to drink since he wants to drink the water directly from the spring. In (366) he used a hand gesture to imitate the climber path. And for (398) he used a hand gesture to imitate climb to the uphill.

In the actions, (49) G: nice chance to take aa.... \{referring to a spot for taking pictures\}; and (338) G: ok...to see.. aa, please.. see first by first... so you can go to see that by one by one that is the waterfall that we will see.. Both of the actions used two types of CS such as stalling/time gaining and non-linguistics signal. The guide used a hesitation device and also used a hand gesture to help to convey the message.

Different with (51) G: aaa some spot here nice to take a picture also you can have a picture with gili island where have you are staying....This actions used two types of CS such as stalling/time gaining and overelaboration. Here the guide used a hesitation device to gain more time.

Meanwhile, in (27) G: aaa which hotel that you stay there?; (177) G: Taiwan..taiwan I think more industry than agriculture... is it?; (224) T: Hudson bay.... I think big harbor...(hesitate)... but I am not sure for the transit, only for fishing I guess....; (287) G: aa garlic village in sembalun and we have the biggest garlic in the world.....in the in the village; and (331) T: aaa after senggigi ... a central one,,, not sure. These actions only used one type of CS it is Stalling or time gaining, the guide use pauses the action to gain enough time till he finds the suitable words, he also uses hesitation device. And for (21) G: it's smaller, a small island in the middle; and (93) G: but its contain dust also... the ashes.

Both of the actions only used one of CS it is over-elaboration. In (21) he should say small island only. And for (93) of course ashes contain dust.

Those are the communication strategies which used by the guide and also the tourists during the interaction. According to Tarone (1983), and Nakatani (2006), it is only used nine types of communication strategies.

Umrah, D. M., Mahyuni, -, \& Syahdan, -. (2018). Communication strategy for English guides: tourism area in Lombok island. International Journal of Social Sciences and Humanities, 2(3), 117-124. https://doi.org/10.29332/ijssh.v2n3.217 


\section{Conclusion}

There is 87 communication strategy action which performed in the interaction between Lombok English speaking guides and the English speaking tourists. Finally, there are nine common communication strategies found out in the interactions, such as message abandonment, topic avoidance, circumlocution, approximation, use the all-purpose word, prefabricated, non-linguistics signal, stalling/time gaining, and over-elaboration. The most common communication strategies or the dominant ones are stalling/time gaining with a total of 18 acts about $20,7 \%$, less dominant are over-elaboration with a total of 4 acts about $74,6 \%$ and the least dominant are circumlocution with a total of 2 acts about 2,3\%. In summary, the guides need to improve their skills and performance to tackle the problems that are present in the

Since this study is limited, it is needed to hold further study about the communication strategies in nonschool based activities. Furthermore, it is needed to conduct studies in the broader context in terms of population and samples in order to get much more information about the communication strategies which need to improve the guide's performance.

\section{Acknowledgments}

Researchers would like to thank all those who have given a prayer, motivation, energy, and material so that this research can be completed on time based on timetable set by the researcher. In particular, the researchers would like to thank my lectures, Who have given encouragement and support to the completion of this research. My unlimited thank is also delivered to my parents who give the invocation and invaluable spirit, so that researcher can complete this thesis and my master degree in English Language Education. 
References

Astawa, I. N., Mantra, I. B. N., \& Widiastuti, I. A. M. S. (2017). Developing Communicative English Language Tests for Tourism Vocational High School Students. International Journal of Social Sciences and Humanities (IJSSH), 1(2), 58-64.

Bialystok, E. (1983). Some factors in the selection and implementation of communication strategies. Strategies in interlanguage communication, 100-118.

Dörnyei, Z. (1995). On the teachability of communication strategies. TESOL quarterly, 29(1), 55-85.

Duranti, A. (2010). Husserl, intersubjectivity and anthropology. Anthropological Theory, 10(1-2), 16-35.

Nakatani, Y. (2006). Developing an oral communication strategy inventory. The modern language journal, 90(2), 151-168.

O'malley, J. M., O'Malley, M. J., \& Chamot, A. U. (1990). Learning strategies in second language acquisition. Cambridge university press.

Saville-Troike, M. (1987). Dilingual discourse: The negotiation of meaning without a common code. Linguistics, 25(1), 81-106.

Tarone, E. (1976). A Closer Look at Some Interlanguage Terminology: A Framework for Communication Strategies. Working Papers on Bilingualism, No. 9.

Tarone, E. (1980). Communication strategies, foreigner talk, and repair in interlanguage 1. Language learning, 30(2), 417-428.

Tarone, E. (1983). Some Thougths on The Nation of Communication Strategy, dalam Faerch, C and Kasper G.(Ed.) Strategies in Interlanguage Communication.

Umrah, D. M., Mahyuni, -, \& Syahdan, -. (2018). Communication strategy for English guides: tourism area in Lombok island. International Journal of Social Sciences and Humanities, 2(3), 117-124. https://doi.org/10.29332/ijssh.v2n3.217 


\section{Biography of Authors}

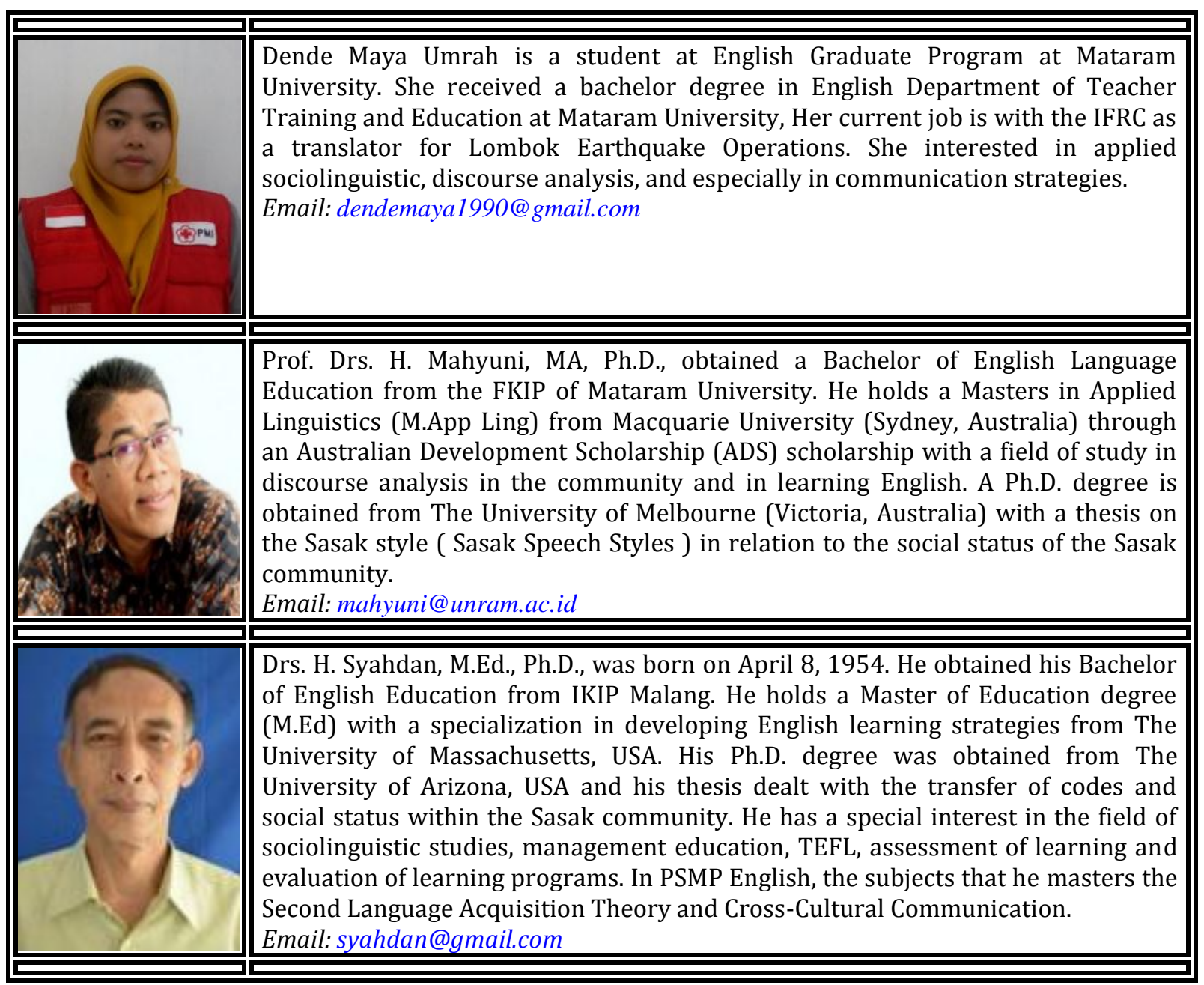

